\title{
SAMPLING BASED UNCERTAINTY ANALYSIS OF $10 \%$ HOT LEG BREAK LOCA IN LARGE SCALE TEST FACILITY
}

\author{
SAMIRAN SENGUPTA ${ }^{1}$, S. K. DUBEY ${ }^{2}$, R. S. RAO ${ }^{2}$, S. K. GUPTA ${ }^{2}$, and V. K RAINA ${ }^{3}$ \\ ${ }^{1}$ Research Reactor Design \& Projects Division, Bhabha Atomic Research Centre, Mumbai-400085, India \\ ${ }^{2}$ Atomic Energy Regulatory Board, Mumbai-400094, India \\ ${ }^{3}$ Reactor Group, Bhabha Atomic Research Centre, Mumbai-400085, India \\ ${ }^{*}$ Corresponding author. E-mail : samiran_sengupta@yahoo.co.in
}

Received August 06, 2010

Accepted for Publication September 29, 2010

Sampling based uncertainty analysis was carried out to quantify uncertainty in predictions of best estimate code RELAP5/MOD3.2 for a thermal hydraulic test (10\% hot leg break LOCA) performed in the Large Scale Test Facility (LSTF) as a part of an IAEA coordinated research project. The nodalisation of the test facility was qualified for both steady state and transient level by systematically applying the procedures led by uncertainty methodology based on accuracy extrapolation (UMAE); uncertainty analysis was carried out using the Latin hypercube sampling (LHS) method to evaluate uncertainty for ten input parameters. Sixteen output parameters were selected for uncertainty evaluation and uncertainty band between $5^{\text {th }}$ and $95^{\text {th }}$ percentile of the output parameters were evaluated. It was observed that the uncertainty band for the primary pressure during two phase blowdown is larger than that of the remaining period. Similarly, a larger uncertainty band is observed relating to accumulator injection flow during reflood phase. Importance analysis was also carried out and standard rank regression coefficients were computed to quantify the effect of each individual input parameter on output parameters. It was observed that the break discharge coefficient is the most important uncertain parameter relating to the prediction of all the primary side parameters and that the steam generator (SG) relief pressure setting is the most important parameter in predicting the SG secondary pressure.

KEYWORDS : Accident Analysis, Latin Hypercube Sampling, LOCA, LSTF, UMAE, Uncertainty

\section{INTRODUCTION}

Thermal hydraulic system codes are complex tools developed to estimate the transient behaviour of nuclear power plants (NPPs) during off-normal conditions. The evaluation of safety margins, the operator training, the optimization of the plant design and related emergency procedures are some of the major applications of these codes. Best estimate computer codes are used to calculate postulated accidents and transients in a realistic way and not in a conservative way. Currently worldwide there is an increasing interest in computational reactor safety analysis to replace conservative evaluation model calculations with best estimate calculations supplemented by quantitative uncertainty analysis. The need to quantify uncertainty in predictions of the best estimate codes comes from the unavoidable approximations embedded in the development and application processes of computational tools including inadequate knowledge of a number of input parameter values.
The performance assessment and validation of these codes and their uncertainty evaluation are among the major objectives of international research programs. As a part of a similar coordinated research project, uncertainty analysis was carried out to quantify uncertainty in predictions of best estimate code RELAP5/MOD3.2 for $10 \%$ hot leg break loss of coolant accident (LOCA) simulation experiment at the Large Scale Test Facility (LSTF). Total failure of high pressure injection system and auxiliary feed water as well as loss of off-site power concurrent with scram is assumed as per experimental boundary conditions. The primary pressure decreases fast and core dry out takes place. The accumulator coolant injection occurs twice. Long term core cooling takes place by the actuation of the low pressure injection system.

This paper mainly describes the post test analysis with uncertainty evaluation of the test (10\% hot leg break LOCA) carried out at the LSTF/ROSA IV, Japan. Test facility description and details of the transient, including transient data for the test and a sample input deck, were 
received from the IAEA. These details were provided by JAEA, Japan, to IAEA. Based on the test facility and experiment, development of an input deck is carried out by incorporating necessary modifications to the sample input deck. Approach/methodologies are finalized to carry out the transient analysis along with the uncertainty and importance analysis. The input deck (nodalisation) is qualified for both 'steady state level' as well as 'on transient level'. Steady state level qualification criteria consist of three parts. i) Details of geometrical parameters (volume, surface area, flow area, elevation, etc.) from the nodalisation scheme and the test facility are compared and errors are generated. ii) Boundary conditions (core power, pressuriser heater power, pump coast down curves, valves opening/closing logic and timing, etc.) of the nodalisation and the test specifications are compared and errors are generated. iii) Various important thermal hydraulic parameters (absolute pressure, differential pressure, fluid temperature, flow rate, collapsed level, clad temperature, heat loss, heat balance, mass inventory, etc.) for steady state, which is derived from the code output, are compared with the experimental data and errors are generated. In all these cases errors are established to be within the acceptable limits specified in UMAE.

For transient level qualification, the capability of the nodalisation scheme to reproduce the relevant thermal- hydraulic phenomena expected in the transient is established. The following steps are performed for qualitative evaluation for transient level qualification: (a) List comparing experimental and code calculation resulting time sequence of significant events (b) Identification/verification of CSNI phenomena validation matrix applicable to this test (c) Phenomenological windows (d) Key phenomena and relevant thermal-hydraulic aspects (e) Visual comparisons between experimental and code calculated relevant parameters time trends. After transient level qualification, uncertainty and importance analysis is carried out.

A Monte Carlo sampling based approach to uncertainty and sensitivity analysis is used to predict (i) what is the uncertainty of the output parameter given the uncertainty of the input parameter? (ii) how important is the individual input parameter with respect to the uncertainty of the output parameter? Uncertainty analysis is done to answer the first question and sensitivity analysis is done to answer the second question. In practice, the implementation of uncertainty analysis and sensitivity analysis are very closely connected on both the conceptual and computational levels. The methodology adopted for the present study consists of the following.

-Expert judgment for the selection of uncertain input parameters.

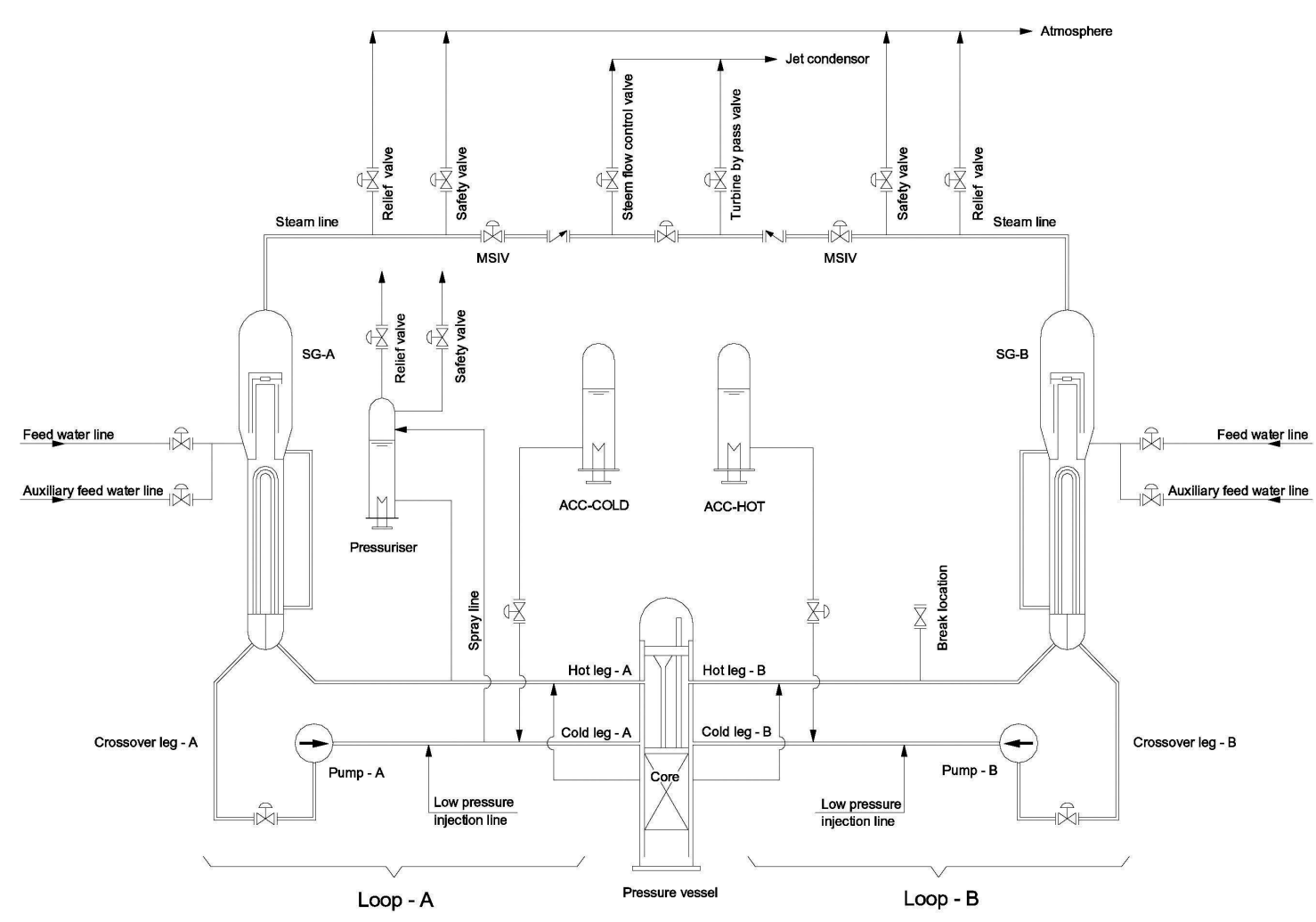

Fig. 1. Simplified Flow Diagram of LSTF for 10\% Hot Leg Break LOCA 
-Calculation matrix generation using Latin hypercube sampling technique.

-Performance of best estimate thermal hydraulic code runs. -Representation of uncertainty analysis results.

-Importance analysis using linear regression.

All the above mentioned steps for uncertainty and importance analysis have been carried out for $10 \%$ hot leg break LOCA, which is described subsequently along with the test facility and the experiment.

\section{LARGE SCALE TEST FACILITY}

The Large Scale Test Facility of ROSA-IV simulates a Westinghouse type four loop pressurized water reactor (PWR) [1] [2]. The thermal power of the prototype PWR (Tsuruga Unit-2 of Japan Atomic Power Company) is 3423 MWt. The LSTF is a full-height and 1/48 volumetrically scaled two loop model (Fig.1) of the PWR. Each loop has an active steam generator (SG) with 141 full-size Utubes (inner diameter-19.6 mm). Hot and cold legs (inner diameter-207 $\mathrm{mm}$ ) are sized to conserve the volumetric scaling (2/48) and the ratio of the length to the square root of the diameter to simulate the flow regime transitions in the horizontal legs. The LSTF simulated fuel rod assembly consists of 1064 heater rods and 104 unheated rods. The LSTF initial core power is $10 \mathrm{MW}$ because of the limitation in the capacity of the power supply in the test facility. This initial power corresponds to $14 \%$ of the volumetrically scaled $(1 / 48)$ nominal core power of the PWR. To obtain prototypical initial fluid temperatures, core flow rate in LSTF is set to $14 \%$ of the scaled nominal flow rate of the PWR. The LSTF instrumentations provide detailed information on the thermal-hydraulic conditions of temperature, level, pressure, differential pressure, flow rate, fluid density, etc. The experiment conducted in this facility, which is considered for the uncertainty analysis, is described below.

\subsection{Experiment of Small Break LOCA}

The break is simulated by using a $31.9 \mathrm{~mm}$ innerdiameter sharp-edge orifice [3] mounted at the downstream of a horizontal pipe. The pipe is connected to the hot leg of the loop-B (i.e., the loop without pressuriser). The orifice flow area corresponds to $10 \%$ of the cold leg cross-sectional area of the reference PWR. The experiment is initiated by opening a break valve located downstream of the break orifice. Initial conditions such as pressuriser (PZR) pressure and fluid temperatures in the hot and cold legs are $15.5 \mathrm{MPa}, 599 \mathrm{~K}$ and $563 \mathrm{~K}$, respectively, according to the reference PWR conditions. The axial profile of the core power is a 9-step chopped cosine with a peaking factor of 1.495 , while the radial profile is a distribution with a peaking factor of 1.51 . Scram and safety injection signals are generated at the PZR pressures of 12.97 and 12.27 MPa, respectively. Based on the decay power curve of the prototype 3423 MWt PWR with 1/48 volumetric scaling factor, the core power decays down to $10 \mathrm{MW}$ after 42 seconds. Since maximum power in the LSTF is limited to $10 \mathrm{MW}$, LSTF core power is kept constant up to 42 seconds in the experiment [4]. Afterwards, LSTF core power is decreased according to the power decay curve of the prototype PWR. Initial pump speed is about $780 \mathrm{rpm}$. For better simulation of the pressure and temperature transient of the reference PWR, the pump speed is increased to $1440 \mathrm{rpm}$ after the break and dropped according to the predetermined coast down curve following the scram signal generation. Initial secondary pressure is raised to $7.3 \mathrm{MPa}$ to limit the primary to secondary heat transfer rate to 10 $\mathrm{MW}$, while $6.1 \mathrm{MPa}$ is the nominal value in the reference PWR. The initial SG secondary side collapsed liquid level is $9.7 \mathrm{~m}$. Set point pressures for opening and closure of SG relief valves (RVs) are 8.18 and $7.82 \mathrm{MPa}$, respectively. Flow area of the RVs is simulated by using a $19.4 \mathrm{~mm}$ inner-diameter sharp-edge orifice. Emergency core cooling system (ECCS) injection from accumulators is actuated at primary pressure of $4.51 \mathrm{MPa}$. Low pressure injection (LPI) is actuated at lower plenum pressure of $1.29 \mathrm{MPa}$. Coolant injection temperatures from the accumulators and LPI are $320 \mathrm{~K}$ and $310 \mathrm{~K}$, respectively. Coolant injection volume in the accumulator tank is $1.68 \mathrm{~m}^{3}$ in loop-A and $0.56 \mathrm{~m}^{3}$ in loop-B. Proportional heaters in the PZR are used to trim the pressure, while backup heaters are used to mitigate system heat losses. Initially, power levels to the proportional and backup heaters are $4.4 \mathrm{~kW}$ and 21.5 $\mathrm{kW}$, respectively. These power levels increase up to 6.6 $\mathrm{kW}$ and $75.7 \mathrm{~kW}$, respectively, after the break. Initial PZR liquid level is $2.7 \mathrm{~m}$. Heaters are turned off soon after the PZR liquid level falls below $1 \mathrm{~m}$.

\section{MODELLING AND NODALISATION QUALIFICATION}

The nodalisation of primary and secondary sides of LSTF used for carrying out small break LOCA analysis using RELAP5/MOD3.2 code [5] is shown in Fig.2. The reactor core is modelled with four parallel channels with nine volumes each using pipe components. The axial power distribution of the fuel simulators is specified as per 9-step chopped cosine distribution. To account for the radial distribution, four fuel rod heat structures with appropriate radial peaking factors are incorporated in modeling. The unheated instrument rods within the core are also modelled. The pressure vessel is modelled with downcomer, lower plenum, core, upper plenum and upper head, along with vessel internals such as core barrel, upper plenum internals, and control rod guide tubes, etc. Each loop is modelled with hot leg, cold leg, crossover leg, pump, SG plenum and SG U tubes. Loop-A is connected to pressuriser through surge line. Each pump is modelled with four quadrant curves. During transient, time dependent pump speed is specified as per the data from the experiment. 


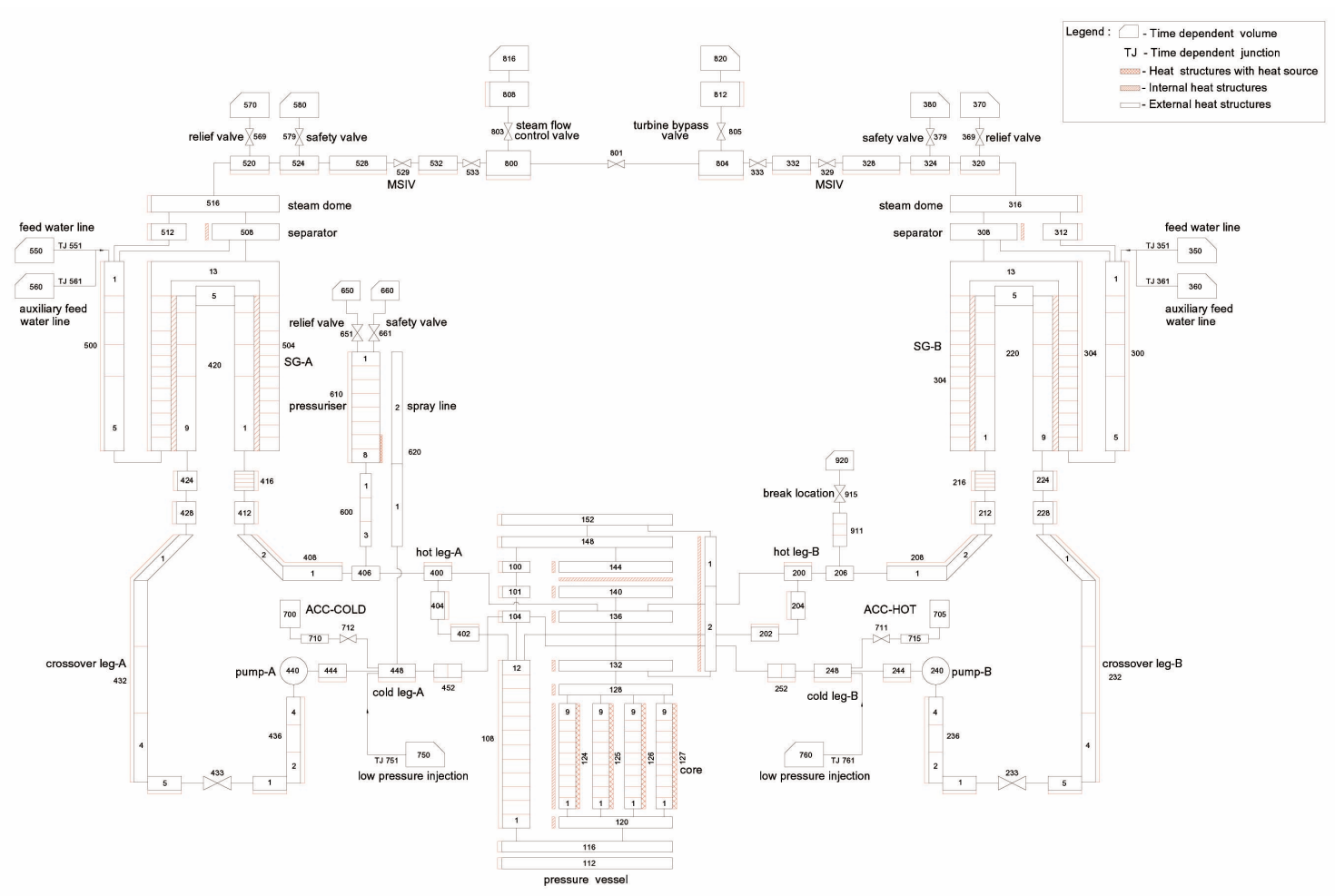

Fig. 2. Nodalisation Scheme of LSTF for $10 \%$ Hot Leg Break LOCA

The break location (915) is modelled with a trip valve in the hot leg of Loop-B (i.e., loop without PZR) and connected to a time dependent volume 920 . The pressure measured in the downstream of the break from the experiment is an input to volume 920. The break area is modelled with cross-sectional area of $8 \mathrm{~cm}^{2}$, hydraulic diameter of 31.9 $\mathrm{mm}$ and discharge coefficient of 1.0.

Appropriate volume and junction control flags are selected to stimulate the physical behaviour of these components. Interfacial friction along with wall friction and thermal non-equilibrium effects are included for all the volumes. A vertical stratification model is also applied. Chocking and non-homogeneous options are applied for all the junctions. Abrupt area change option is activated at locations where sharp change in flow area takes place, such as junctions between pressure vessel and piping, loop piping and SG plenum, SG tubes and SG plenum, pressuriser and surge line, loop piping and pressuriser spray line, etc. Abrupt area change option is also applied in all the valve locations and break locations. A momentum flux option is used for all the junctions except for locations where large variation in flow area is seen, e.g. hot \& cold leg piping to pressure vessel (PV). For the junction from upper plenum of PV to hot leg, momentum flux is used for the "to" cell and not used for the "from" cell. Whereas, for the junction from the cold leg to downcomer of PV, momentum flux is used for the "from" cell and not used for the "to" cell. A side oriented horizontal stratification vapor pull through/liquid entrainment model is used in the break location. A counter current flow limitation model is applied for the vertical junctions at downcomer annulus.

The emergency core cooling system (ECCS) is connected from the accumulator (ACC-COLD) to volume 448 of loop-A and from accumulator (ACC-HOT) to volume 248 of loop-B. Pressuriser heater is modelled with the help of heater power as a function of time available from the experiment. Pressuriser relief valve and safety valve are modelled with specific control logic of opening and closure.

Nodalisation of the secondary side of the SG includes external downcomer, steam generator, separator, separator bypass, steam dome, and steam header line. Steam line relief valves, safety valves and main steam isolation valves (MSIVs) are modelled using motorized valve option with specific opening and closure logic.

All the components of primary and secondary sides are modelled with proper insulation and material properties to account for their heat losses to the atmosphere. Various heat structures considered in the simulation includes i) reactor vessel wall, upper head, vessel bottom, core barrel, upper plenum internals, guide tubes, upper core support plate, unheated instrument rods, unheated section of 


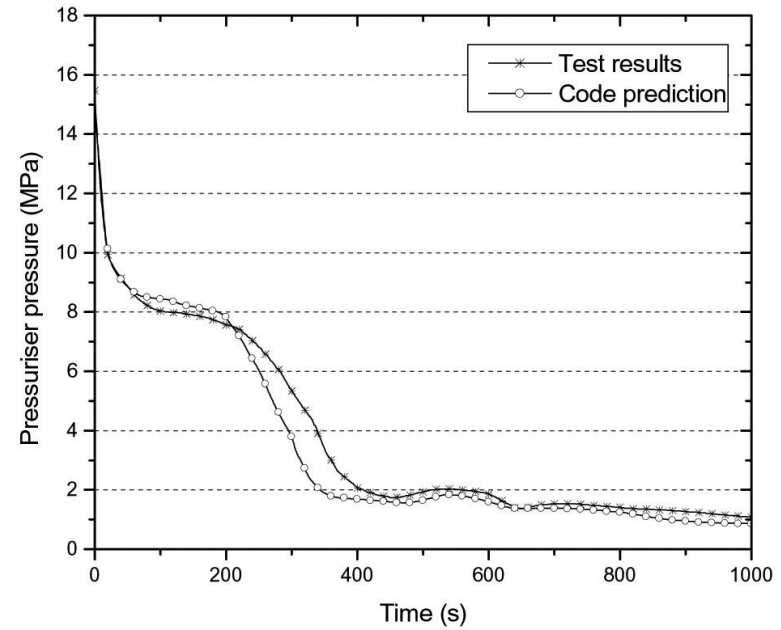

Fig. 3. Pressuriser Pressure

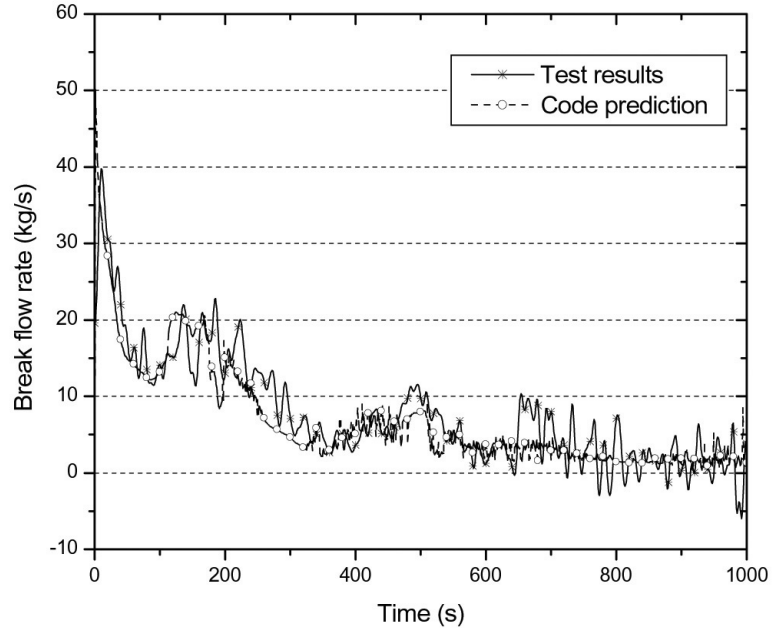

Fig. 4. Break Flow Rate heater rods ii) pressuriser wall, top head, bottom flange, heaters iii) Loop piping iv) SG primary side, tube bundle and v) SG secondary side boiler wall, separator, external downcomer pipe, steam dome, piping.

The nodalisation scheme is qualified by systematically applying the procedures led by uncertainty methodology based on accuracy extrapolation (UMAE) [6] for 'steady state level' and 'on transient level', which are described in the following sections.

\subsection{Steady State Level Qualification}

Steady state level qualification of the nodalisation scheme is carried out [7] by comparing overall geometrical parameters (volume, elevation, heat transfer area, metal volume, flow area, etc.) of the nodalisation input with the data of the test facility. It is seen that all the geometrical parameters meet the acceptance criteria. Volume vs. height curves for the pressure vessel, SG-A and SG-B, are compared and it is found that volume distribution in the code and in the experiment are well within the acceptable error band (10\%). Acceptance criteria for boundary conditions (such as core power, PRZ power, core bypass flow, pump initial velocity, pump coast down curve, valve opening closing logic, timings, thermo physical properties, pressure setting for injection, volume of injected liquid, etc.) are checked with input nodalisation and found to be satisfactory. All significant thermal-hydraulic parameters necessary to identify the facility/plant status are selected from the experiment (such as heat balance, absolute pressure, fluid temperature, fuel rod surface temperature, heat losses, flow rate, level and mass inventory) and compared with the steady state parameters obtained from the code. The pressure distribution of Loop-A, Loop-B and pressure vessel are also compared and found to be within acceptance criteria (10\%).

\subsection{Transient Level Qualification}

Transient level qualification of the nodalisation scheme is carried out [8] by comparing the experimental and the code calculation resulting time sequence of significant events. It is demonstrated that time of occurrence for most of the events obtained from code is in good agreement with the experimental value. Identification of CSNI phenomena validation matrix applicable for the experiment is prepared and gradation of the test facility and the code is made by observing a phenomenon in the experiment and predicting similar phenomenon in the computer simulation. A number of phenomenological windows (i.e., time spans in which a unique relevant physical process mainly occurs) are identified from the experiment and compared with the results obtained from the code. Key phenomena and relevant thermal hydraulic aspects are defined for this transient and characterized by numerical values of significant parameters such as single value parameters, time sequence of events, integral parameters, etc. Visual comparisons between experimental and code calculated relevant parameter time trends for various thermal hydraulic parameters show that these values are in good agreement for most of the parameters, except for some of the parameters that have minor disagreements as described below.

The pressure at the top of the pressuriser shown in Fig. 3 agrees well with the experimental data. The results indicate that the fast depressurization of the primary side takes place due to large flow through the break (Fig.4) during the early stage of the subcooled liquid blowdown phase. However, predicted flow rates through the break during the two phase flow and single phase vapor flow show some discrepancy with the experimental data. It is observed in the code prediction that single phase blowdown takes place up to 36 seconds. Subsequently, two phase 
blow down takes place. After 267 seconds, single phase vapor flow takes place through break when hot leg of loop-B is empty of liquid.

Under-prediction of the two phase break flow results in lower mass discharge from the primary system. Therefore, calculated core liquid level prediction is higher than the values in the experimental data, as shown in Fig.5. However, after 150 seconds, break flow is over-predicted, which causes fast primary pressure loss and an earlier accumulator injection following loop seal clearing. It is found that loop seal clearing takes place at about 304 seconds, after which the core level is recovered. This causes a short uncovered time for the fuel rods and leads to a lower temperature rise of the fuel rod surface during dry out, as shown in Fig.6.

The pressure prediction at the SG dome shown in

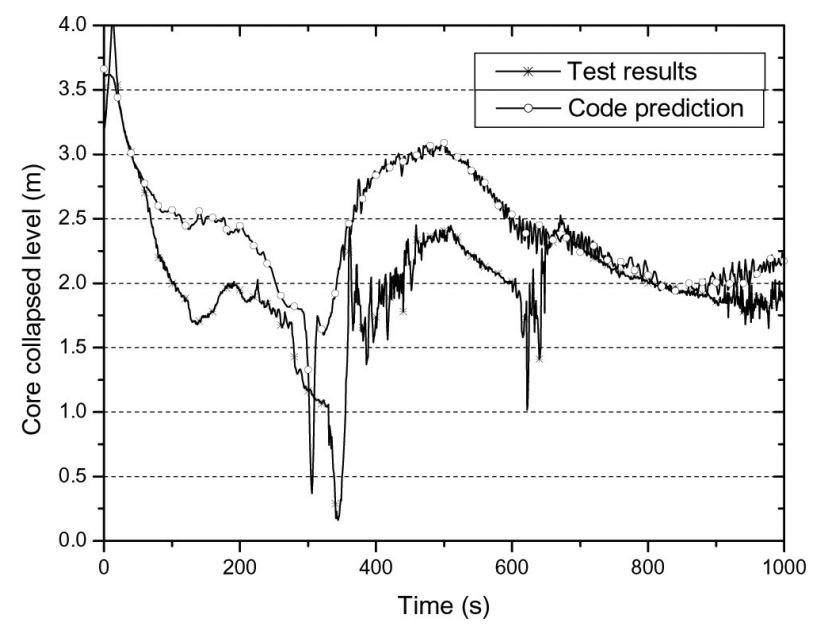

Fig. 5. Core Collapsed Level

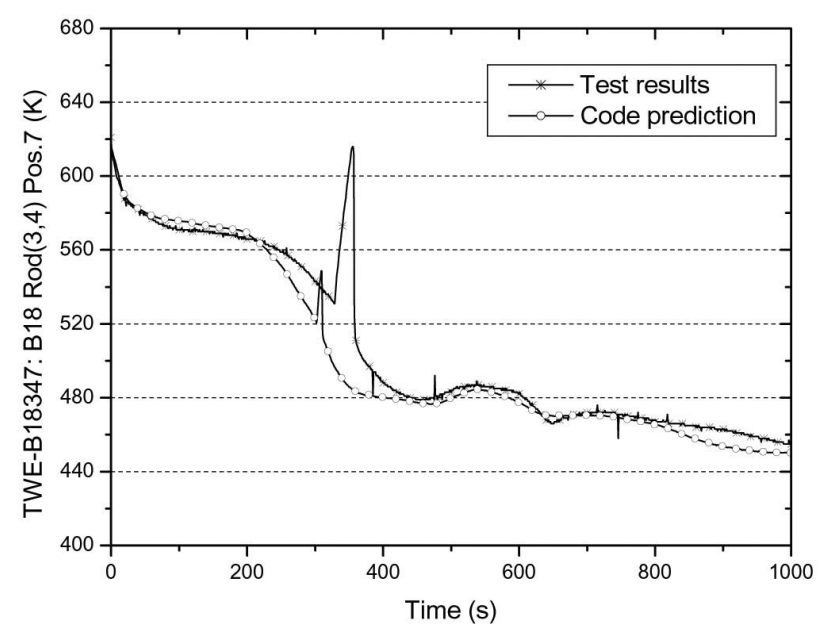

Fig. 6. Fuel Rod Surface Temperature
Fig. 7 is in good agreement with the experimental data. During fast depressurization of the primary side, the scram signal is generated when the PZR pressure decreases to 12.97 $\mathrm{MPa}$. The scram signal generation causes the closure of the SG main steam isolation valves (MSIVs) and the coast down of the primary coolant pumps. The SG secondary side pressure increases rapidly after the closure of the MSIV till it reaches the SG relief pressure setting. The SG secondary pressure fluctuates between 8.18 and $7.82 \mathrm{MPa}$ with the opening and closure of the relief valves (RVs). The SG secondary side collapsed liquid level (Fig. 8) also fluctuates in response to the RV opening. The SG secondary side collapsed liquid level is maintained since the primary pressure falls to a level lower than that of the secondary-side pressure after 186 seconds and SG no longer acts as a heat sink.

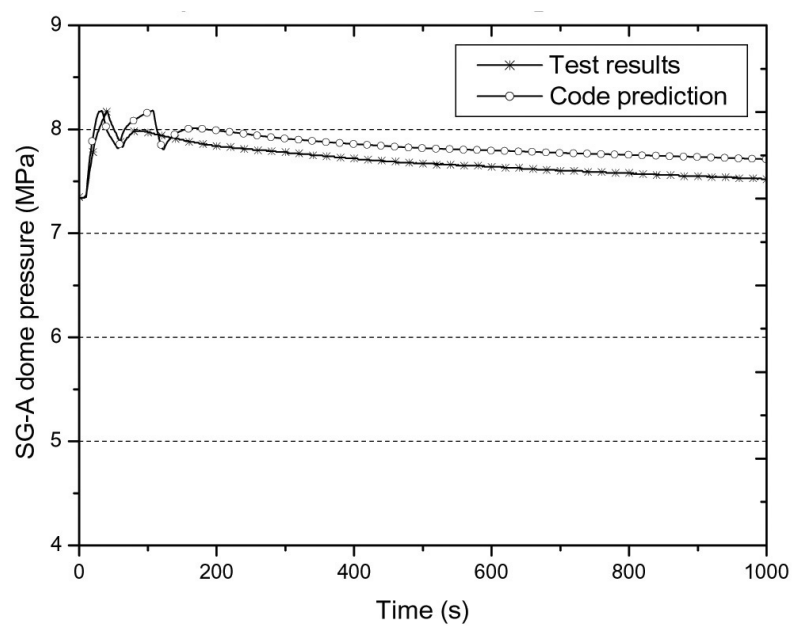

Fig. 7. Pressure of SG-A

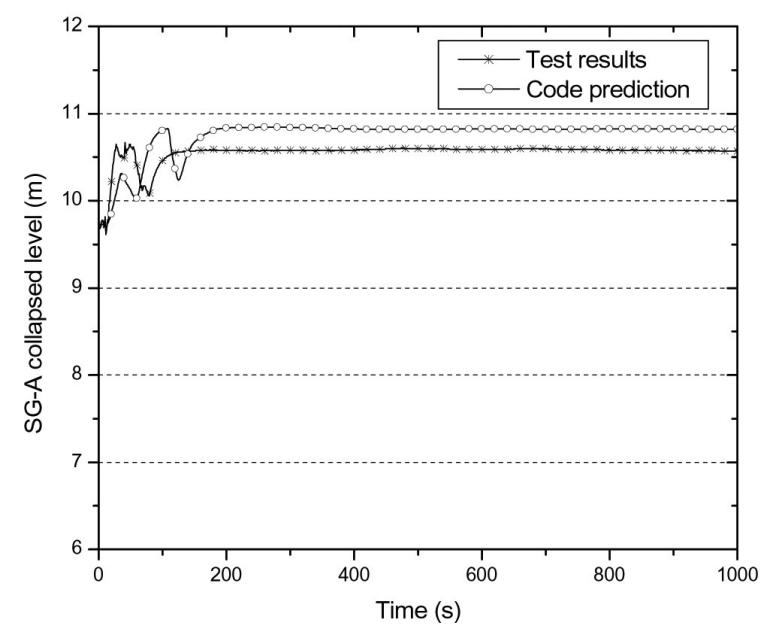

Fig. 8. Collapsed Level of SG-A 
The ECCS flow injection is initiated when the primary pressure decreases to $4.51 \mathrm{MPa}$. The accumulator coolant injection occurs twice in the experiment (Fig.9). However, code prediction results show injection occurring twice for accumulator (ACC-COLD) only. The variation of the ACC-COLD pressure and injection point pressure are shown in Fig.10. The prediction clearly shows that ACCCOLD injection starts at 294 seconds, when injection pressure is less than ACC-COLD pressure. The ECCS injection tries to recover the injection pressure. Once injection pressure increases and becomes equal to ACCCOLD pressure, injection flow stops at 487 seconds. Based on the system pressure, when injection pressure falls below ACC-COLD pressure, injection is initiated for the second time from 599 seconds. The injection continues up to 703 seconds till the ACC-COLD set level

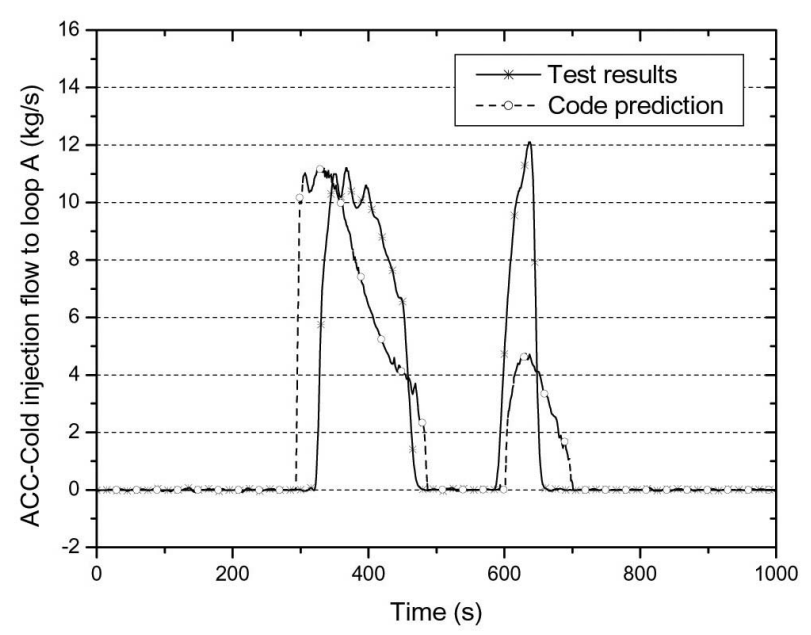

Fig. 9. AccumulAtor (ACC-COLD) Injection Flow Rate

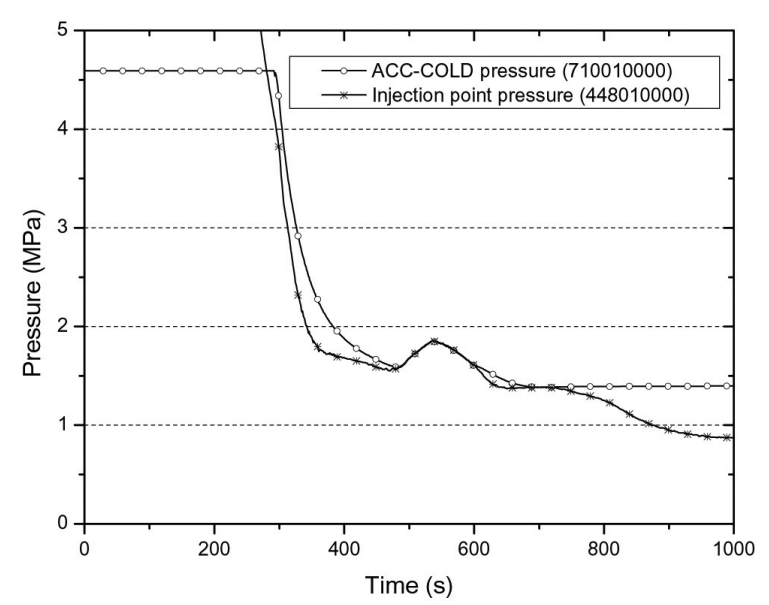

Fig. 10. Accumulator (ACC-COLD) and Injection Point

Pressure is reached to isolate the accumulator. The code prediction shows that the ECCS actuation takes place earlier than that of the experiment because the predicted primary pressure is lower than that of the experiment during this period. The maximum injection flow rate from the accumulator is predicted to be less than that of the experiment during the second injection. This may be due to the sudden decrease in core pressure due to condensation, which is not well predicted by the code. The coolant injection from the accumulators is stopped based on the accumulator level set point.

The LPI system in loop-A is actuated when the pressure vessel lower plenum pressure decreases to $1.29 \mathrm{MPa}$ at 797 seconds. Further cooling of the core is continued by the LPI system and fluid temperature gradually comes down, as shown in Fig.11.

From the results of the steady state and transient, it is observed that most of the code calculated parameters are in good agreement with the experimental ones. Therefore, overall simulation of this transient is qualified as per qualitative qualification procedure.

\section{UNCERTAINTY ANALYSIS}

Qualified nodalisation (mentioned in the previous sections) is used to carry out the uncertainty and importance analysis based on the Monte Carlo sample based approach. Screening sensitivity analysis is carried out for various uncertain input parameters, which may affect the results of the transient analysis. These parameters are selected based on expert judgment. Screening sensitivity analysis is done to determine the relative significance of each input parameter in order to reduce the number of model input parameters for which an extensive uncertainty analysis is

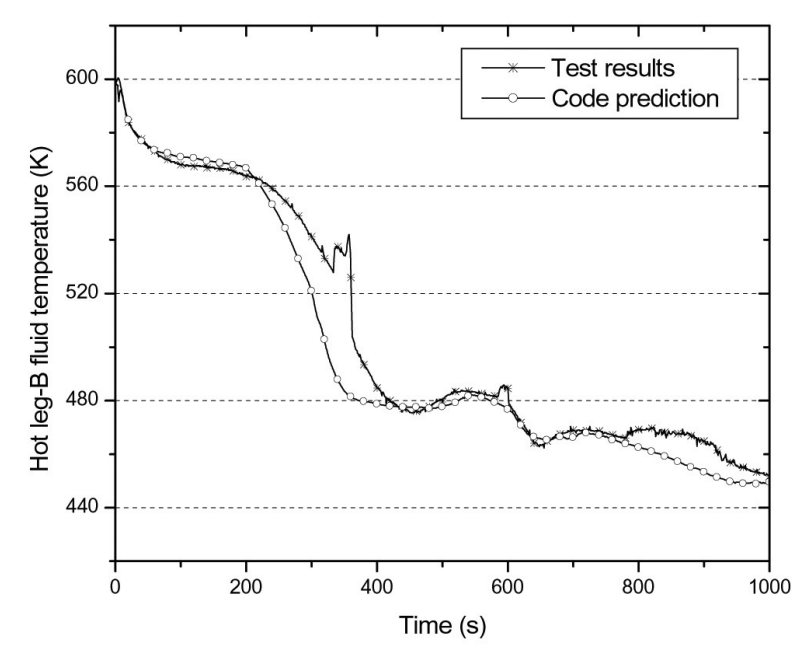

Fig. 11. Hot Leg- B Fluid Temperature 
needed [9]. As an example, break flow rate variation with respect to three uncertain input parameters (discharge coefficient at break location, accumulator isolation set level and SG relief valve set pressure) are shown in Fig. 12 to Fig.14. For each uncertain input parameter with minimum value (1), maximum value (2) and nominal value (n), the results are compared with the experimental data.

Based on the observations of screening sensitivity analysis, the key input parameters, which have significant

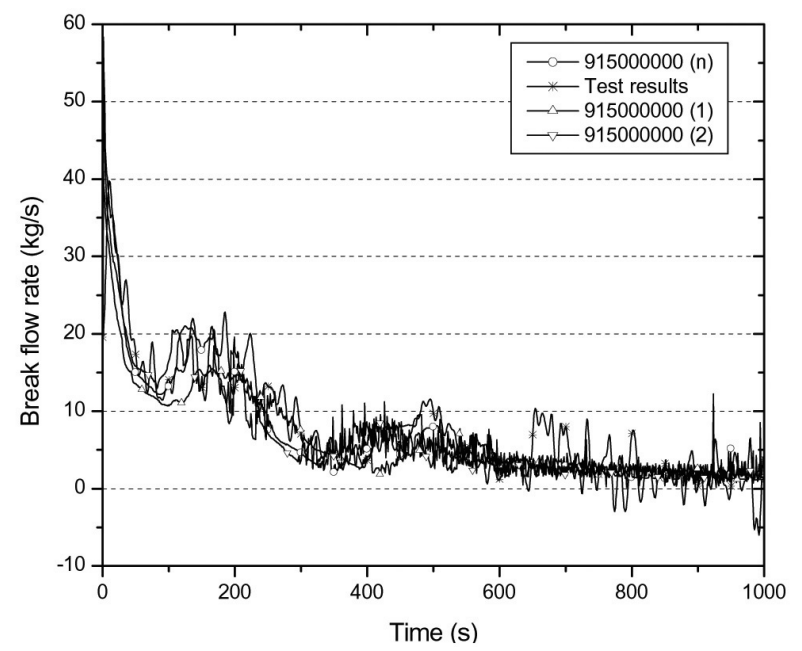

Fig. 12. Effect of Break Valve Discharge Coefficient on Break Flow Rate impact on the required Figures-of-merit, are decided to carry out the uncertainty analysis. The key input parameters and their minimum, nominal and maximum values are indicated in Table 1 . The ranges of these parameters are selected based on code defaults, expert judgment and experimental uncertainties.

Using the above parameters RELAP5/MOD3.2 runs are taken and sixteen important output parameters (pressuriser pressure, SG-B pressure, SG-A pressure,

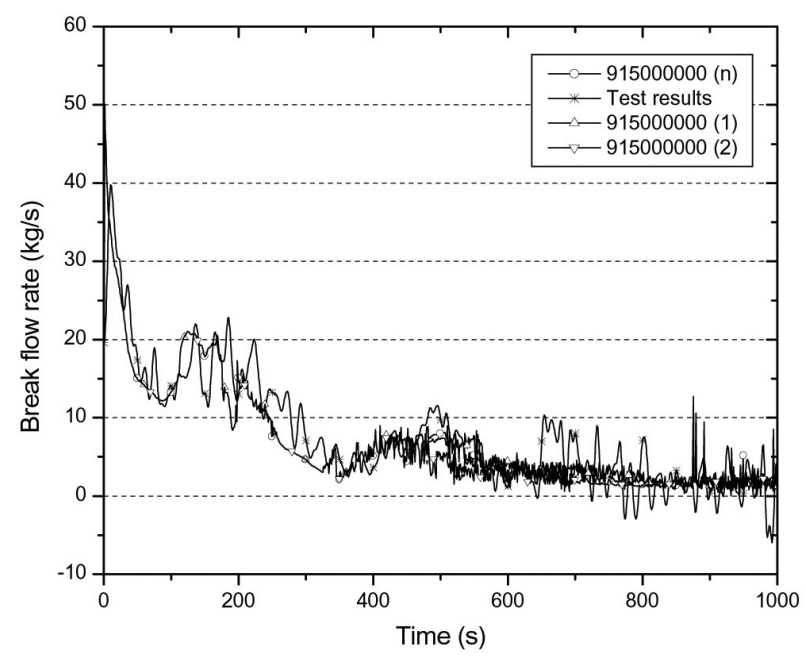

Fig. 13. Effect of Accumulator Isolation Set Level on Break Flow Rate

Table 1. Variation in Input Parameters

\begin{tabular}{|c|c|c|c|}
\hline Input Parameters & Minimum & Nominal & Maximum \\
\hline Discharge coefficient of SG relief valve & 0.85 & 1.0 & 1.15 \\
\hline Set point of accumulator injection pressure $(\mathrm{MPa})$ & 3.9 & 4.1 & 4.3 \\
\hline ACC-HOT injection stop level (m) & 5.2 & 5.4 & 5.6 \\
\hline Discharge coefficient of accumulator & 0.85 & 1.0 & 1.15 \\
\hline ACC-COLD fluid temperature $(\mathrm{K})$ & 314 & 319 & 324 \\
\hline ACC-HOT fluid temperature (K) & 319 & 324 & 329 \\
\hline Discharge coefficient at break location & 0.85 & 1.0 & 1.15 \\
\hline Primary heat loss coefficient $\left(\mathrm{W} / \mathrm{m}^{2} / \mathrm{K}\right)$ & 2.25 & 3.0 & 3.75 \\
\hline Secondary heat loss coefficient $\left(\mathrm{W} / \mathrm{m}^{2} / \mathrm{K}\right)$ & 2.25 & 3.0 & 3.75 \\
\hline Relief valve set pressure (MPa) & 8.03 & 8.18 & 8.33 \\
\hline
\end{tabular}


SG-A collapsed level, SG-B collapsed level, Loop-A flow rate, Loop-B flow rate, flow through break, downcomer fluid temperature, differential pressure in pressure vessel, differential pressure in heated core, ACC-COLD pressure, ACC-HOT pressure, ACC-COLD injection rate, ACCHOT injection rate, and rod surface temperature) are selected from the code output. These output parameters are selected such that the transient can be mainly represented by these parameters and uncertainty analysis of these parameters can be carried out.

In the present study, the uncertainty in the selected model parameters mentioned in Table 1 is characterized by the uniform distribution. A stratified Monte Carlo sampling method known as Latin hypercube sampling (LHS) is used in the uncertainty propagation analysis. This method is commonly used because its efficient stratification properties allow for the extraction of a large amount of uncertainty and sensitivity information with relatively small sample size [10]. In this sampling technique, a design matrix of order ( $\mathrm{n} \mathrm{X} \mathrm{k)}$ is prepared, where $\mathrm{n}$ is the number of code runs to be taken and $\mathrm{k}$ is the number of input variables. In the LHS technique, number of sampling for $\mathrm{k}$ input variables is sufficient if it is $4 / 3 \mathrm{k}$. However, it is better to obtain as many samples as possible ( $2 \mathrm{k}$ to $5 \mathrm{k}$ ). Accordingly, 50 code runs are performed for ten input parameters, which is considered to be adequate.

Based on the upper bound and lower bound of the input parameters mentioned in Table 1, 50 random samples are generated to form the design matrix using the LHS technique. Subsequently, 50 sets of code runs are performed by taking one set of input parameters from the design matrix; the time trends of the sixteen output parameters are extracted from the code output for each

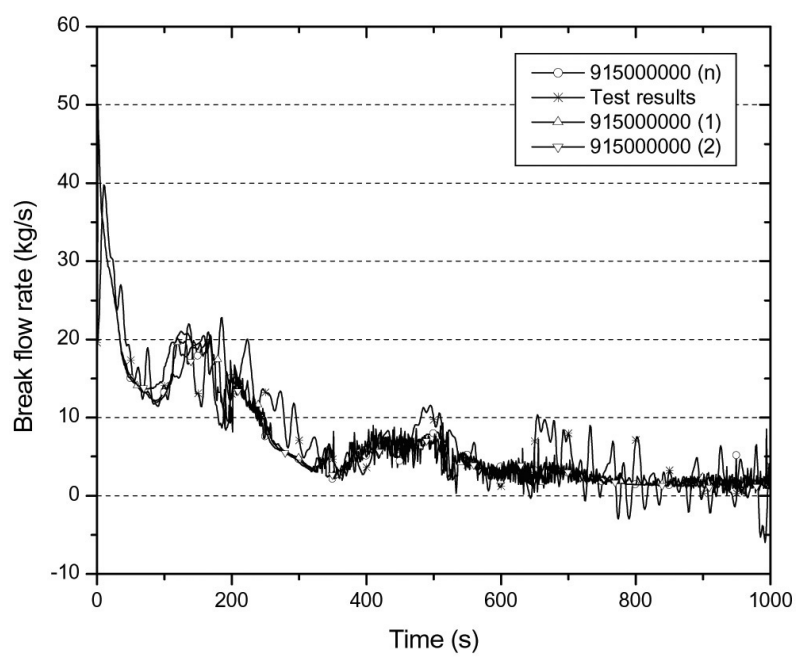

Fig. 14. Effect of SG Relief Set Pressure on Break Flow Rate run. All these output parameters for 50 runs are stored. Afterwards, for each time, all these data are sorted in ascending order in a separate data file. Then, rank is given to all these 50 values for each time. From these ranks the mean, median, $5^{\text {th }}$ and $95^{\text {th }}$ percentiles are evaluated. The median value is the middle value of $\mathrm{N}$ ordered values (stored in ascending order). The $5^{\text {th }}$ and $95^{\text {th }}$ percentiles are calculated using the following equation. The $\mathrm{p}^{\text {th }}$ percentile of $\mathrm{N}$ ordered values is obtained by first calculating the rank (r) using the following equation, rounding to the nearest integer and taking the value that corresponds to the calculated rank.

$$
\mathrm{r}=\mathrm{N} / 100 *(\mathrm{p})+1 / 2
$$

Based on the above formulation, the $5^{\text {th }}$ percentile corresponds to rank 3 and the $95^{\text {th }}$ percentile corresponds to rank 48 . The mean, median, $5^{\text {th }} \& 95^{\text {th }}$ percentiles of output for nominal input and experimental values are compared as shown in Fig.15 to Fig.25. Although the continuous graphs are shown for the mean, $5^{\text {th }}$ percentile, $95^{\text {th }}$ percentile and median output, it should be noted that all the points from one figure are not from the same set of input.

Figure 15 shows the uncertainty in PRZ pressure. The results show that during the two-phase blowdown, the magnitude of the uncertainty band is greater compared to the remaining part of the transient. It is clear that mean $\&$ median values lie between the uncertainty band and that the experiment data matches well with these results.

The uncertainty in the SG-A dome pressure prediction

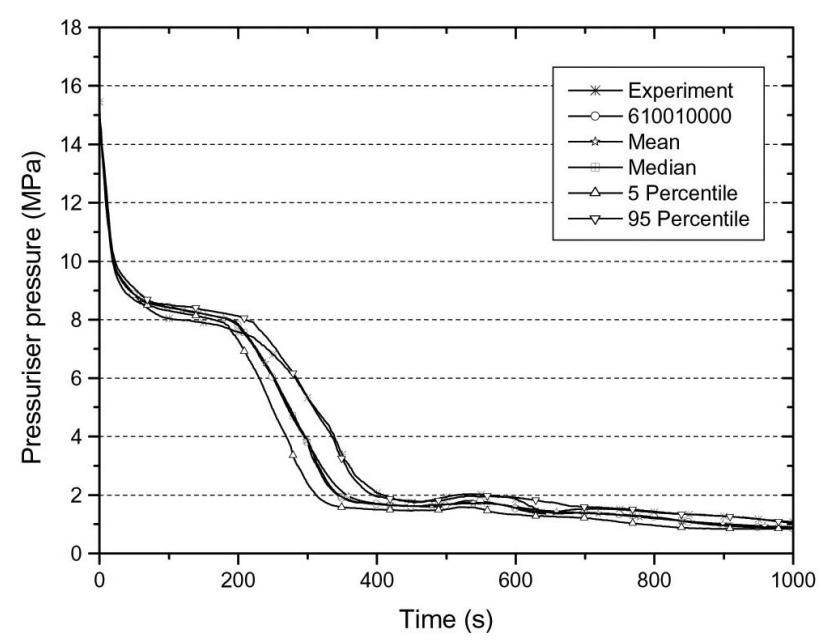

Fig. 15. Uncertainty in Pressuriser Pressure 


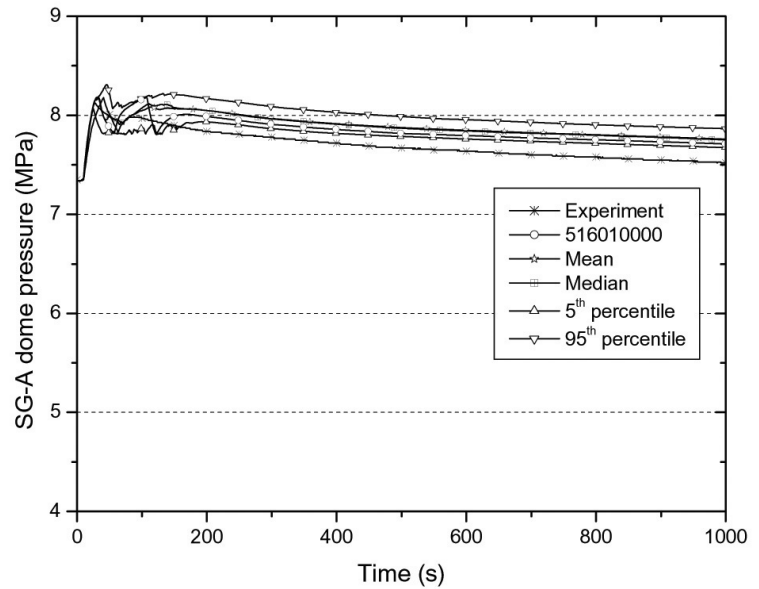

Fig. 16. Uncertainty in SG-A Dome Pressure

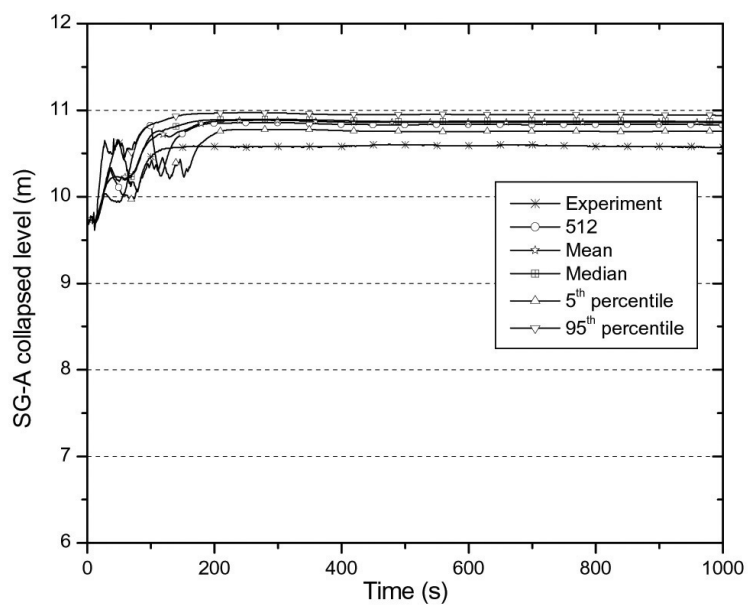

Fig. 17. Uncertainty in SG-A Collapsed Level

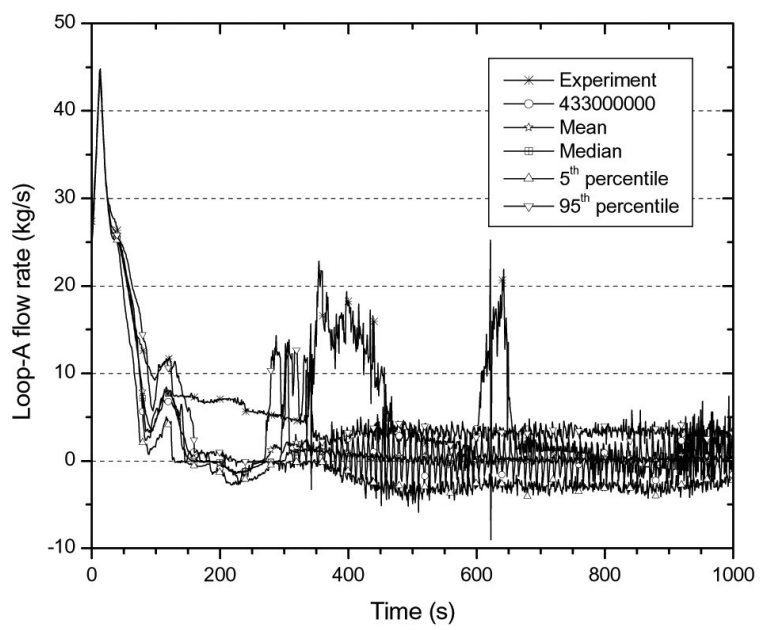

Fig. 18. Uncertainty in Loop-A Flow Rate

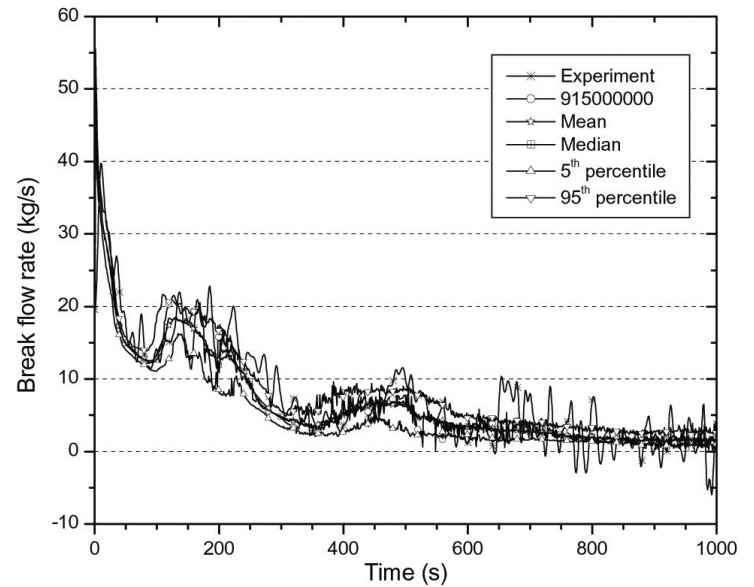

Fig. 19. Uncertainty in Flow Rate Through Break Location

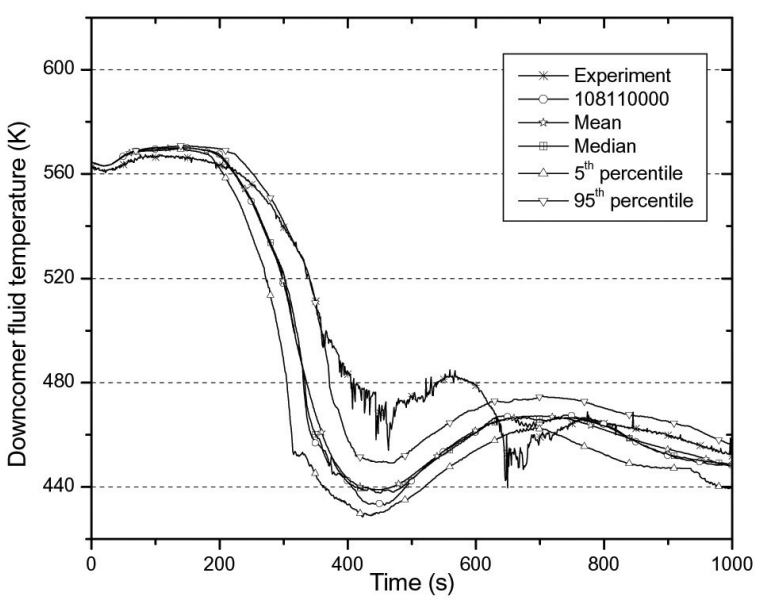

Fig. 20. Uncertainty in Downcomer Fluid Temperature

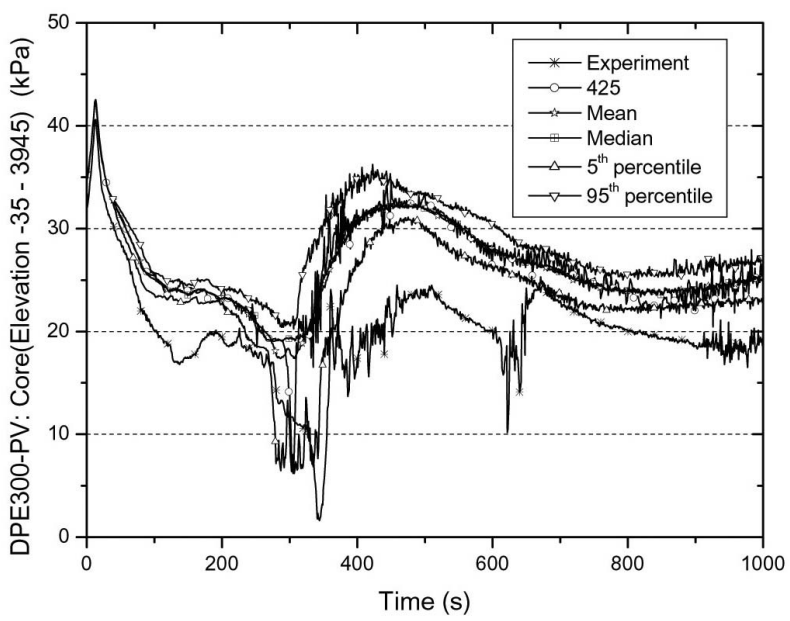

Fig. 21. Uncertainty in Core Pressure Drop 
is shown in Fig.16. A similar trend of results is observed for the SG-B dome pressure. Though mean and median results show similar trends with respect to the experimental data, beyond 150 seconds of transient, the experimental data show a lower steam dome pressure than the values of the output parameter between the uncertainty band. This may be due to the lower prediction of release of steam through the SG relief valve in the code calculation. Figure 17 shows the plot for the SG-A collapsed level. As mentioned, due to the lower steam release rate prediction in the analysis, the collapsed level predicted is higher than that of the experimental data. Similar results are observed for the SG-B collapsed level.

Figure 18 shows the uncertainty in flow rate of LoopA. Predicted flow rates within the uncertainty band match well with the experimental data except in the region where injection from the accumulator takes place. During first time injection there is an increase in flow rate, as was observed in the experiment. However, the amount of increase predicted is lower. Since the initiation of injection that takes place in the analysis is earlier, there is a time shift also. Accumulator injection starts early in the analysis because the decrease in primary pressure is greater during the blowdown phase (200 to 400 seconds) in the analysis than in the experimental observation. During second time accumulator injection, experimental data again show an increase in Loop flow rate. However, this phenomenon is not observed in the analysis. For Loop-B flow rate also, a similar discrepancy in results between the experiment and the analysis is observed.

Figure 19 shows the plot of the flow rate through the break location. It can be clearly seen that a very good agreement in trends between experimental value and output values is observed.

The results for fluid temperature in the downcomer

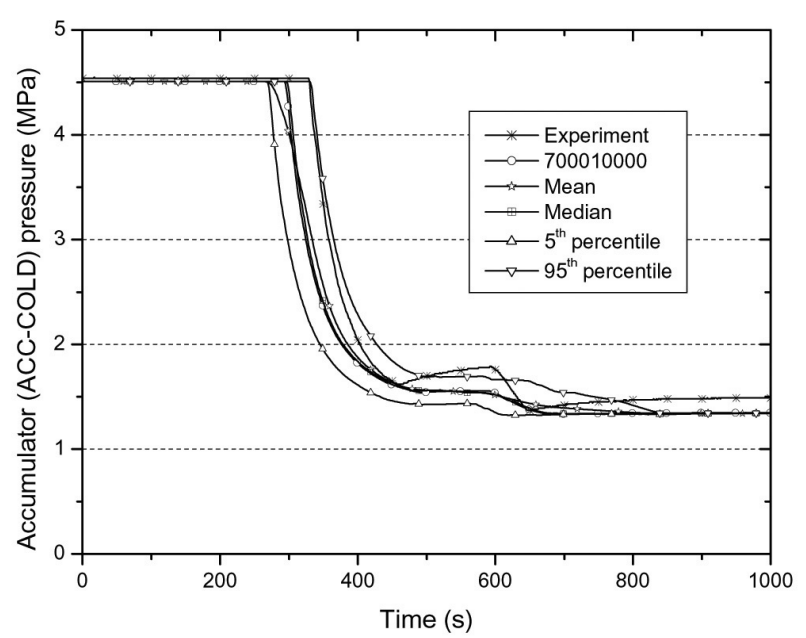

Fig. 22.Uncertainty in Accumulator (ACC-COLD) Pressure show that experimental values are within the uncertainty band (Fig.20) during most of the time except between 350 to 700 seconds. This may be due to the fact that loop flow rate and heat transfer rate are not well predicted during this time, which decides the fluid temperature of the downcomer.

Figure 21 shows the uncertainty plot of the pressure drop across the core. From the output results, it can be seen that the experimental value is not always within the uncertainty band of the code prediction. However, the time trends are similar to that observed in the experiment. Differential pressure in the pressure vessel also shows similar trends.

The uncertainty in the pressure of the accumulator ACC-COLD (Fig.22) shows that experimental data and output for nominal values of input have the same trends. It is also observed that the experimental data are well within the uncertainty band except for the limited period at the last part of the transient. The uncertainty in pressure of the accumulator ACC-HOT also shows a similar trend of results.

Figures 23 and 24 show the uncertainty in predicting the injection flow rates from accumulators ACC-COLD and ACC-HOT, respectively. The results indicate that the accumulator injection takes place earlier than that of the experiment because the predicted primary pressure is lower during this period. The maximum predicted injection flow rate from the accumulator is less than that of the experiment during second time injection. This may be due to the sudden decrease in core pressure due to condensation, which is not well predicted by the code.

Figure 25 gives a plot of the fuel rod surface temperature. It is observed that the experimental data are well within the uncertainty band except for the limited period during core uncovery causing dryout condition.

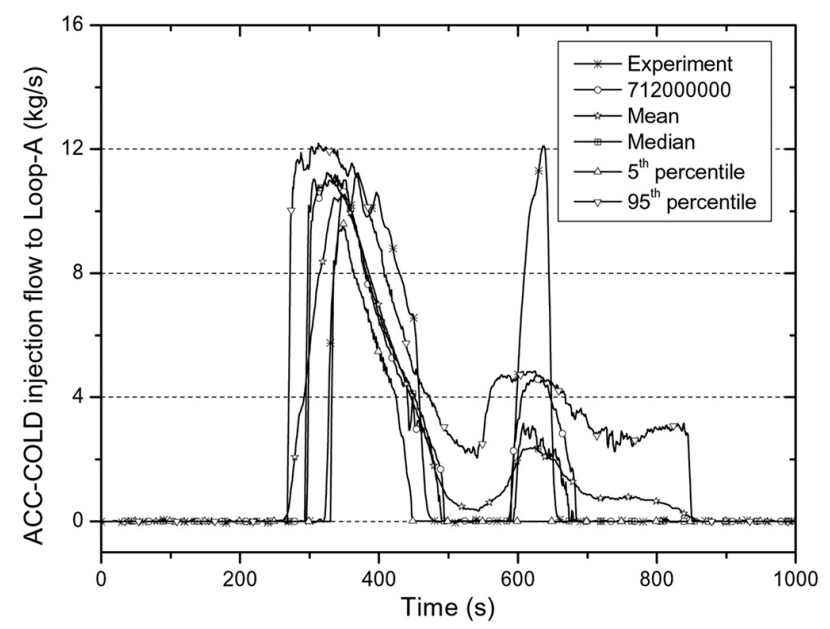

Fig. 23. Uncertainty in Accumulator (ACC-COLD) Flow Rate 


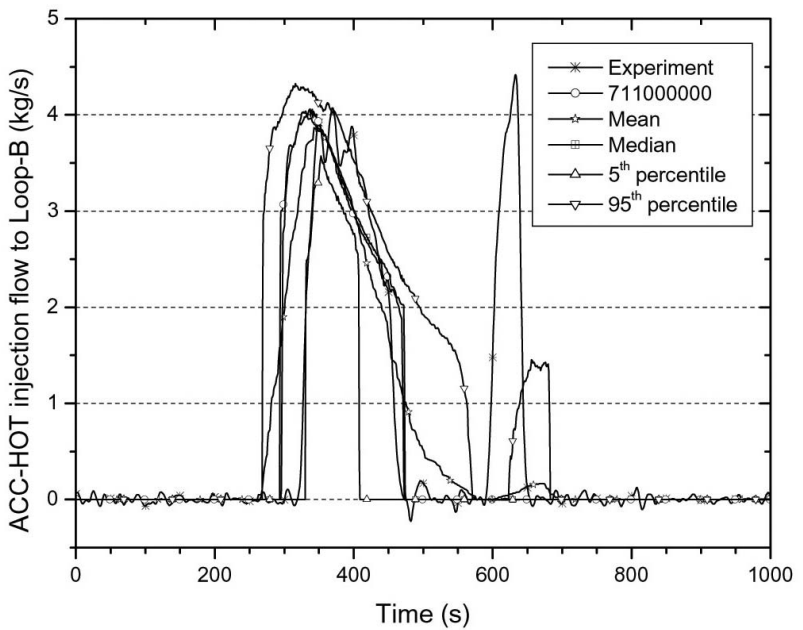

Fig. 24. Uncertainty in Accumulator (ACC-HOT) Flow Rate

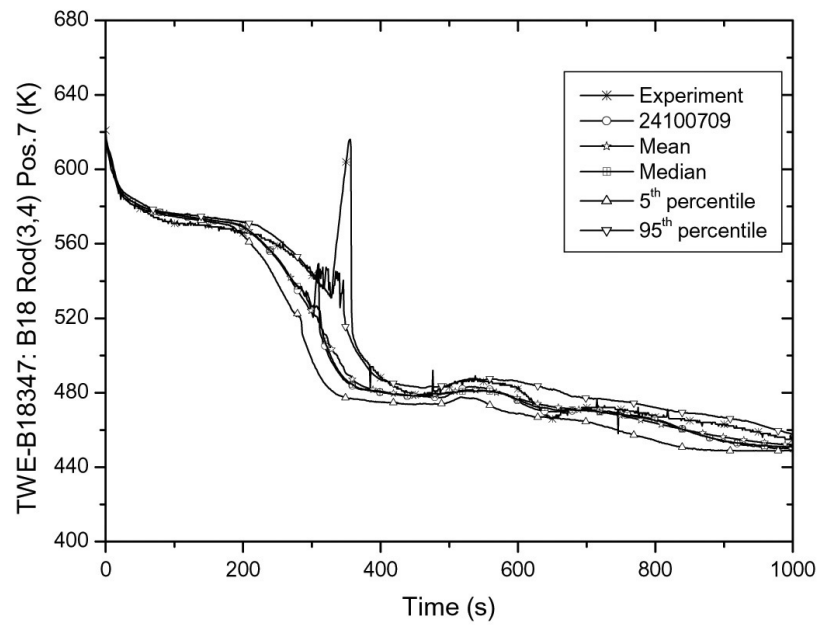

Fig. 25. Uncertainty in Fuel Rod Surface Temperature

Table 2. Standard Regression Coefficients

\begin{tabular}{|c|c|c|c|c|c|c|c|c|}
\hline Parameter & $\begin{array}{c}\text { Break flow } \\
\text { at } 300 \\
\text { seconds }\end{array}$ & $\begin{array}{c}\text { Primary } \\
\text { pressure at } \\
300 \text { seconds }\end{array}$ & $\begin{array}{c}\text { SG-A } \\
\text { pressure at } \\
300 \text { seconds }\end{array}$ & $\begin{array}{c}\text { SG-B } \\
\text { pressure at } \\
300 \text { seconds }\end{array}$ & $\begin{array}{c}\text { Rod surface } \\
\text { temperature } \\
\text { at } 300 \\
\text { seconds }\end{array}$ & $\begin{array}{c}\text { ACC-COLD } \\
\text { flow rate } \\
\text { at } 400 \\
\text { seconds }\end{array}$ & $\begin{array}{l}\text { ACC-HOT } \\
\text { flow rate at } \\
400 \text { seconds }\end{array}$ & $\begin{array}{l}\text { Coe } \Delta \mathrm{P} \text { at } \\
400 \text { seconds }\end{array}$ \\
\hline $\begin{array}{c}\text { SG relief valve } \\
\text { discharge coefficient }\end{array}$ & 0.04365 & 0.02758 & 0.04490 & -0.24185 & -0.05771 & 0.00445 & 0.01373 & 0.01823 \\
\hline $\begin{array}{l}\text { Accumulator } \\
\text { injection pressure }\end{array}$ & 0.05990 & -0.00848 & 0.10937 & -0.04716 & -0.02149 & -0.18158 & -0.24441 & -0.12608 \\
\hline Injection stop level & 0.00368 & -0.01291 & -0.05767 & -0.09635 & 0.03132 & -0.01751 & -0.05336 & -0.07510 \\
\hline $\begin{array}{c}\text { Accumulator } \\
\text { discharge coefficient }\end{array}$ & -0.02565 & -0.01249 & 0.10619 & 0.02042 & -0.00816 & -0.05370 & -0.06816 & 0.09718 \\
\hline $\begin{array}{l}\text { ACC-COLD fluid } \\
\text { temperature }\end{array}$ & -0.00283 & -0.02553 & -0.06672 & 0.16830 & -0.07136 & -0.10052 & -0.12673 & -0.21882 \\
\hline $\begin{array}{l}\text { ACC-HOT fluid } \\
\text { temperature }\end{array}$ & 0.00933 & -0.05049 & -0.04494 & 0.04117 & -0.07282 & -0.07863 & -0.10723 & 0.02719 \\
\hline $\begin{array}{l}\text { Break discharge } \\
\text { coefficient }\end{array}$ & -0.94780 & -0.97890 & -0.05065 & -0.21163 & -0.93624 & -0.91082 & -0.88749 & 0.79867 \\
\hline Primary heat loss & 0.06912 & 0.03446 & -0.02192 & -0.12743 & -0.04463 & 0.06001 & 0.06229 & -0.00646 \\
\hline Secondary heat loss & 0.02162 & 0.03273 & -0.03974 & -0.16202 & -0.03112 & -0.01812 & -0.02549 & -0.01599 \\
\hline SG relief pressure & -0.01132 & -0.04629 & 0.85761 & 0.76223 & 0.01036 & 0.02606 & -0.00390 & 0.00564 \\
\hline $\mathrm{R}^{2}$ & 0.89141 & 0.97131 & 0.76953 & 0.7652 & 0.87621 & 0.87133 & 0.87346 & 0.70707 \\
\hline
\end{tabular}


The predicted value is much lower than the experimental data. This may be due to the short predicted uncovered time for the fuel rods in the analysis.

\subsection{Importance Analysis}

Based on the results obtained from the 50 runs mentioned in the previous sections, importance analysis is carried out to evaluate the degree to which an input parameter affects the model output results. A number of approaches, in conjunction with a sampling based uncertainty analysis, are available to carry out the importance analysis [11]. In the present study, regression analysis and partial correlation are used to determine the importance analysis results. Regression analysis provides an algebraic representation of the relationships between an output parameter and one or more of the input parameters. In the present study, the linear relationship between output and input parameters is assumed and standardised regression coefficients (SRCs) are evaluated. The SRCs provide a useful measure of variable importance with (i) the absolute values of the coefficients providing a comparative measure of variable importance and (ii) the sign of the coefficient indicating whether input and output parameters tend to move in the same direction or in the opposite direction as long as the input parameters are independent.

The main output parameter considered is the break flow, which finally dictates the primary pressure and fuel rod surface temperature. These output parameters are compared during the initiation of accumulator injection (at 300 seconds in the experiment). To know the behavior of output parameters after the reflood phase (at 400 seconds) the parameters considered are ACC-COLD and ACCHOT injection flow rate and core pressure differential. To compare the secondary side parameters, pressure of SG-A and SG-B is considered. The SRCs for all these parameters are shown in Table 2. The goodness of fit value $R^{2}$ is calculated based on the following equations.

$$
\begin{gathered}
R^{2}=\frac{\sum_{i=1}^{n S}\left(\hat{y}_{i}-\bar{y}\right)^{2}}{\sum_{i=1}^{n S}\left(y_{i}-\bar{y}\right)^{2}} \ldots \ldots . . \\
\hat{y}=b_{0}+\sum_{j=1}^{n X} b_{j} x_{j} \ldots \ldots . .
\end{gathered}
$$

and

$$
\bar{y}=\sum_{i=1}^{n S} y_{i} / n S
$$

where $\mathrm{nS}=$ number of samples; $\mathrm{nX}=$ number of input variables; $\mathrm{y}=$ output variable;
This value provides a measure of the extent to which the regression model can match the observed data. Specifically, when the variation of the regression model is small, then the corresponding $\mathrm{R}^{2}$ value is close to 1 , which indicates that the regression model is accounting for most of the uncertainty on the output variable. Conversely, a value close to 0 indicates that the regression model is not very successful. The values of $R^{2}$ are indicated in Table 2 . It is observed that the $\mathrm{R}^{2}$ values tend more towards 1 .

\section{CONCLUSION}

Steady state and transient levels qualifications for the hot leg break LOCA in LSTF has been carried out using the thermal hydraulics system code RELAP5/MOD3.2. From the results of the steady state and transient, it is observed that most of the code calculated parameters are in good agreement with the experimental ones. However, certain discrepancies are observed during injection from accumulator into Loop-B during second time injection due to system pressure not dropping below accumulator ACC-HOT pressure.

Uncertainty and importance analysis has been carried out by using order statistics with the LHS technique to quantify the uncertainty in predictions of the best estimate code RELAP5/MOD3.2. Uncertainty plots in the output parameters indicate that the uncertainty band for the primary pressure during blowdown phase (200 to 400 seconds) is more than that of the remaining period. Similarly, a larger uncertainty band is observed relating to accumulator injection flow during reflood phase. Regression analysis is carried out and standard rank regression coefficients are computed. The value of $R^{2}$ is evaluated and found to tend more towards 1 , which indicates that the regression model is able to account for most of the uncertainty on the output variables. Based on the standard regression coefficients, it is observed that the break discharge coefficient is the most important uncertain parameter relating to the prediction of all the primary side parameters and the SG relief pressure setting is the most important parameter in predicting the SG secondary pressure.

\section{ACKNOWLEDGEMENTS}

We are thankful to the IAEA for providing us details of the LSTF/ROSA-IV test facility and the sample input deck under the framework of CRP.

\section{REFERENCES}

[ 1 ] K. Tasaka, M. Tanaka, M. Suzuki, Y Kukita, Y. Koizumi, Y. Anoda, et. al., "ROSA-IV Large Scale Test Facility System Description”. JAERI-M 84-237, Tokai Research Establishment, JAERI (1985). 
[2] T. Takeda, "ROSA/LSTF Experimental Data Transfer for IAEA CRP on Evaluation of Uncertainties in Best Estimate Accident analysis", Nuclear Safety Research Center, JAEA, Japan (2007).

[ 3 ] Y. Kukita, K. Hirata, H. Gotou, Y. Koizumi, Y. Anoda, H. Kumamaru, et. al.,"Data Report for ROSA-IV LSTF 10\% Hot Leg Break Experiment Run SB-HL-O2”. JAERI-M 90039, Department of Reactor Safety Research, JAERI, Tokaimura, Japan (1990).

[4] K. Tasaka, M. Suzuki, Y. Kukita, Y. Anoda, H. Kumamaru, H. Asaka, et. al., "Supplemental Description of ROSAIV/LSTF with no.1 Simulated Fuel-ROD Assembly", JAERIM 89-113, Department of Reactor Safety Research, Tokai Research Establishment, JAERI, Tokaimura, Japan (1989).

[ 5] The RELAP5 Code Development Team, "RELAP /MOD3 Code manual”, NUREG/CR-5535, INEL-95/0174 June (1995),

[6] A. Petruzzi, F. D'Auria, W. Giannotti, "Description of the Procedure to Qualify the Nodalisation and to Analyze the Code Results," DIMNP NT 557(05), University of Pisa, Italy (2005).
[7] S. K. Gupta, S. K. Dubey, Samiran Sengupta, R. S. Rao, "First year progress report on IAEA CRP on uncertainty evaluation in best estimate accident analysis of NPPs", Mumbai, June (2007).

[8] Samiran Sengupta, S. K. Dubey, K. Sasidharan, S. K. Gupta, V. K. Raina, "Post-test analysis of $10 \%$ hot leg break LOCA of LSTF using RELAP5/MOD3.2", 20 National and 9th International ISHMT-ASME Heat and Mass Transfer Conference, Mumbai (2010).

[9] M. Khatib-Rahbar, E. Cazzoli, M. Lee, H. Nourbakhsh, R. Davis, and. E. Schmidt, "A probabilistic approach to quantifying uncertainties in the progression of severe accidents", Nuclear Science \& Engineering, 102, 219-259 (1989).

[10] Sang-Ryeol Park, Won-Pil Baek, Soon-Heung Chang and Byung-Ho Lee, "Development of an uncertainty quantification method of the best estimate large LOCA analysis", Nuclear Engineering and Design, 135, 367-378 (1992).

[11] D. M. Hamby, "A Review of Sensitivity Analysis Techniques (U)", WSRC-MS-93-576, Westinghouse Savannah River Company, March (1994). 